\title{
ESTUDO DE MIGRAÇÃO DA ENZIMA POLIGALACTUNORASE INCORPORADA EM FILMES BIODEGRADÁVEIS DE ACETATO DE CELULOSE
}

\author{
Bruna Lana Oliveira Peixoto; Marília Lordêlo Cardoso Silva²; \\ 1. Bolsista FAPESB, Graduando em Engenharia de Alimentos, Universidade Estadual de Feira \\ de Santana, e-mail: blpeixoto3@gmail.com
}

2. Orientador, Departamento de Tecnologia, Universidade Estadual de Feira de Santana, e-mail: marilialordelo@yahoo.com.br

PALAVRAS-CHAVE: Migração, Poligalactunorase, Embalagens

\section{INTRODUÇÃO}

As embalagens de alimentos são estratégias importantes que podem ser decisivas quanto ao benefício referente à competitividade na indústria de alimentos. Portanto, há constante desafio visando atender às exigências dos consumidores, fornecendo embalagens modernas, práticas, que preservem os alimentos e sejam viáveis ambiental e economicamente (SOARES, et al., 2009). Nesse contexto, novas linhas de pesquisa têm surgido nas últimas décadas com o objetivo de desenvolver embalagens que interajam com o produto embalado, trazendo, portanto, uma vantagem adicional para estas. Muitas dessas embalagens ativas têm sido desenvolvidas a partir de matérias-primas naturais e renováveis, tanto a matriz polimérica como os aditivos funcionais incorporados, apresentando assim o caráter da biodegradabilidade (MACHADO, 2011 apud SANTANA et al., 2013). Visto a importância da embalagem para o alimento e a necessidade em torno do seu aperfeiçoamento, este trabalho objetivou fortalecer a rede de pesquisa em busca de alternativas que consigam expandir o conhecimento em torno dos filmes ativos biodegradáveis a fim de futuras aplicações industriais. O objeto do trabalho são filmes de acetato de celulose incorporados com enzima poligalacturonase, que foram avaliados quanto à migração para diferentes meios.

\section{MATERIAL E MÉTODOS}

Reagentes:

Pectinase (P2401/ Sigma-Aldrich Brasil Ltda.), consistindo de um extrato bruto liofilizado de pectinases de Rhizopus sp com atividade de poligalacturonase (PG, ED 3.2.1.15) média de $500 \mathrm{U} / \mathrm{g}$ de sólido, Acetato de celulose (AC) (Rhodia, Brasil), Acetona (Dinâmica, Brasil), Desoxicolato de sódio (0,15\%), Ácido tricloroacético (90\%), Dodecil sulfato de sódio 0,5\% em NaOH 0,1N, Ácido nítrico. O reagente para quantificação de proteína (QuantiProTM BCA Assay Kit) foi obtido da Sigma-Aldrich Procedimento Experimental:

Os filmes foram elaborados em 3 repetições no delineamento inteiramente casualizado (DIC). Afim de verificar o efeito de diferentes concentrações da enzima incorporada no filme de acetato de celulose, desenvolveu-se três diferentes tratamentos, sendo eles denominados da seguinte forma: Controle AC: filme de acetato de celulose sem enzima (FAC-C), Tratamento 1: filme de acetato de celulose contendo $0.05 \%$ da enzima comercial (FAC-PG0,05) e Tratamento 2: filme de acetato de celulose contendo $0,1 \%$ da enzima comercial (FAC-PG0.1). A minuciosidade do experimento torna necessário cuidados em relação a todo material e reagentes utilizados, sendo assim, foi 
realizada a descontaminação da vidraria com ácido nítrico a $10 \%$ e posteriormente, a esterilização em autoclave $\left(121^{\circ} \mathrm{C}\right.$ por $\left.15 \mathrm{~min}\right)$ do material que necessitou ser estéril.

a) Elaboração dos Filmes de Acetato de Celulose (AC):

Os filmes foram produzidos pela técnica de evaporação de solvente (solvent casting), por espalhamento da solução filmogênica em placa de vidro plana, com auxílio de bastão de vidro. Para a elaboração dos filmes foram pesados em pote de vidro, $3 \mathrm{~g}$ de acetato de celulose, adicionados $30 \mathrm{~mL}$ de acetona, fechados e vedados com fita adesiva. Após 24 horas de repouso, a mistura foi homogeneizada com bastão de vidro para, então, ser acrescentada a enzima conforme o tratamento (FACPG0.05-0,0015g e FACPG0.1 - 0,0030g). Para uma incorporação completa da enzima no filme, agitou-se vigorosamente com bastão de vidro, deixando-o descansar por 10 minutos para a completa eliminação das bolhas de ar. Em seguida o filme foi espalhado sobre as placas de vidro previamente limpas com acetona e deixado em repouso por 15 minutos até secagem completa.

b) Montagem do Experimento:

Para o estudo da quantificação da migração da enzima, foram realizadas soluções de diferentes reagentes com a finalidade de se verificar o comportamento da enzima poligalacturonase em cada meio. Diante disso, em cada repetição de filme elaborado, foi conduzido um experimento de migração nos meios simulantes (pectina, sacarose, mistura sacarose: ácido cítrico, água e ácido ascórbico). Antes da montagem do experimento, todo material utilizado foi esterilizado em autoclave a $121^{\circ} \mathrm{C}$ por 15 min para eliminar microrganismos capazes de elevar a quantidade de proteína no meio, alterando, assim, a quantificação de proteínas no final do processo. As soluções foram distribuídas em volumes de $13 \mathrm{~mL}$ para tubos Falcon estéreis $(15 \mathrm{~mL})$, em capela de fluxo laminar. Com a finalidade de prevenir as possíveis contaminações, realizou-se, também, a esterilização dos filmes $\left(5 \times 1 \mathrm{~cm}^{2}\right)$ a partir da radiação UV. Posteriormente, os filmes foram imersos com o auxílio de uma pinça estéril. A eliminação de interferentes e a quantificação foram realizadas em 4 tempos $(5,10,15$ e 30 dias).

c) Quantificação de Proteína:

c.1) Eliminação de Interferentes:

A realização desta etapa foi de extrema importância devido as interações que ocorrem entre os componentes dos meios estudados e os reagentes utilizados no método de quantificação. Dessa forma, foi introduzida essa etapa recomendada pelo próprio fabricante do kit utilizado no procedimento de quantificação de proteína com a finalidade de impedir esse fator.

Na etapa de eliminação de interferentes, procedeu-se a substituição do meio por água deionizada estéril totalizando 3 precipitações e lavagens sucessivas. Tubos eppendorf de 2,0 ml previamente descontaminados foram utilizados a partir da adição de $1,7 \mathrm{ml}$ da solução, $150 \mathrm{ul}$ de desoxicolato de sódio (0.15\%), e $150 \mathrm{ul}$ de solução de ácido tricloroacético. Após centrifugação por 10 minutos a $13000 \mathrm{rpm}$, foram pipetados $1,8 \mathrm{ml}$ do sobrenadante, permanecendo no tubo $0,2 \mathrm{~mL}$ de pellet, solubilizado com 20 uL de dodecil sulfato de sódio $0,5 \%$ em $\mathrm{NaOH} 0,1 \mathrm{~N}$ e dissolvido com $0,280 \mathrm{~mL}$ de água. $\mathrm{O}$ procedimento foi realizado por mais 2 vezes.

c.2) Quantificação de proteína:

O teor de proteína foi determinado pelo método do ácido bicinconínico (BCA), utilizando o QuantiProTM BCA. A reação foi conduzida em poços de microplacas com alíquotas de $125 \mu \mathrm{L}$ do reagente de trabalho adicionados à $125 \mu \mathrm{L}$ da amostra. A absorbância foi lida a $560 \mathrm{~nm}$ em espectrofotômetro Multiskan Go 3.2 e comparada com a curva padrão. 


\section{RESULTADOS E/OU DISCUSSÃO:}

As Figuras 1 e 2 mostram a concentração de proteína nos diferentes tempos de avaliação para os filmes de acetato de celulose incorporados com a enzima poligalactunorase. Em relação aos dois critérios de análise do experimento os quais se baseiam na avaliação da quantidade de proteínas ao longo do tempo (5, 10, 15 e 30 dias) e na avaliação da migração com o aumento da concentração de enzima (tratamento $1 \mathrm{e}$ tratamento 2), percebe-se uma incoerência dos resultados obtidos. Essa observação pode ser feita com base nas barras de erro. Os altos valores de concentração de proteína nos ensaios de 30 dias, decorreu de contaminação microbiana, verificada pela turbidez do meio e presença de hifas, indicando que para o método de esterilização utilizado, não se pode manter o meio estéril por 30 dias. Diante desse fato, concluiu-se que houve a presença de interferentes capazes de tornar esses resultados desconformes ao apresentar elevados desvios provocados por elementos que não foram controlados devido a inexistência de fatores que os identificavam.

Nos testes realizados na tese apresentada por Wurlitzer (1962), com utilização do n-heptano como meio simulante, foi possível detectar a migração de ácido sórbico e triclosan nos filmes de Poli(Cloreto de Vinilideno), indicando a eficiência antimicrobiana nos testes in vitro, com a formação de halos de inibição proporcionais a concentração de triclosan incorporado. Outro trabalho envolvendo migração é o de Cunha et.al., (2007), que desenvolveu filme de base celulósica incorporado com lactase para redução do teor de lactose presente no leite. Esse estudo apresentou resultados significativos na redução da lactose a partir da migração da enzima, possibilitando a utilização desse filme no revestimento de embalagens para acondicionar leite. A embalagem antimicrobiana à base de poli (tereftalato de etileno) (PET) desenvolvida por Corradini et. al, 2013, e incorporada com lisozima também obteve resultados satisfatórios diante dos objetivos estabelecidos. Visto isso, percebe-se uma grande variedade de trabalhos com migração de enzimas que se tornaram um grande potencial para o desenvolvimento de novas embalagens ativas capazes de inovar a indústria alimentícia.

Esses estudos nos levam a acreditar que a partir da utilização de métodos mais sofisticados de eliminação de interferentes, faz-se possível quantificar de forma coerente a migração da enzima poligalactunorase nos filmes de acetado de celulose, viabilizando, assim, a elaboração de embalagens ativas incorporadas por essas enzimas que podem ser uteis na comercialização de produtos com melhores características.

Figura 1: Concentração de proteína ao longo do tempo nos filmes de acetato de celulose contendo $0.05 \%$ da enzima comercial (FACPG0.05).

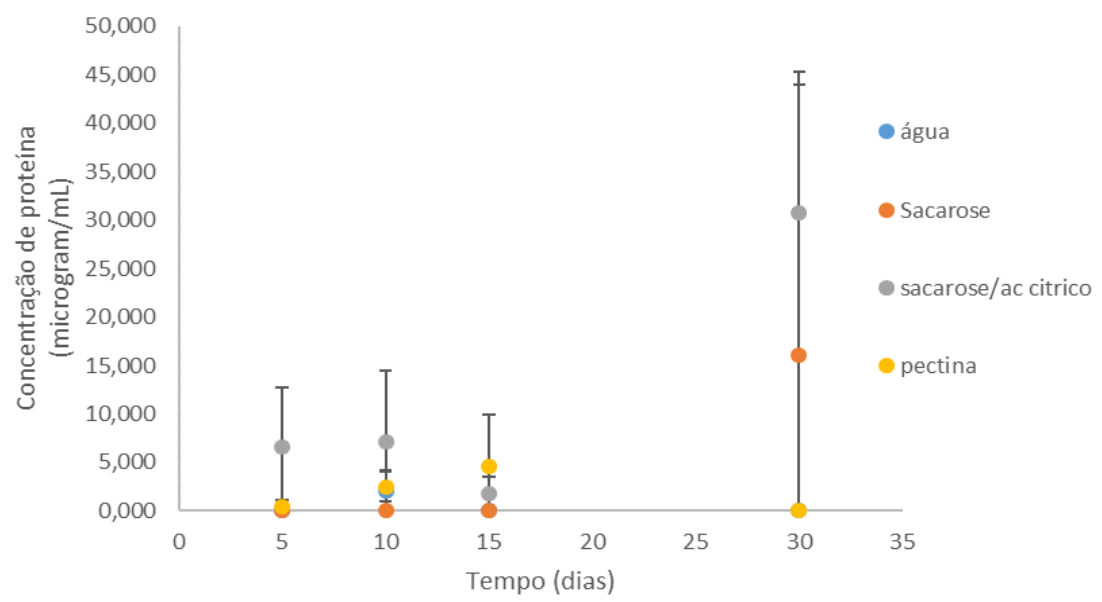


Figura 2: Concentração de proteína ao longo do tempo nos filmes de acetato de celulose contendo $0,1 \%$ da enzima comercial (FACPG0.1).

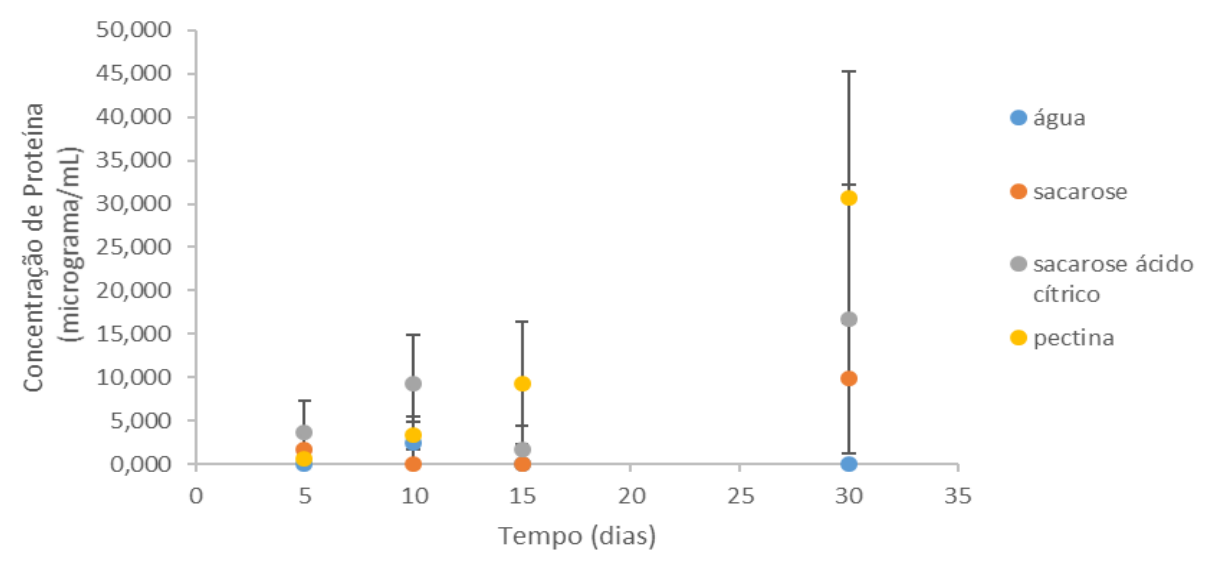

\section{CONSIDERAÇÕES FINAIS}

O objetivo geral era estudar a migração da poligalacturonase incorporada em filmes de acetato de celulose. No entanto, apesar de serem utilizados procedimentos com a finalidade de eliminar quaisquer tipos de elementos interferentes, não foi possível eliminá-los de maneira eficaz, inviabilizando a análise dos resultados. Logo, não se pode afirmar se houve migração da enzima poligalactunorase nos meios estudados, ou se a migração foi mascarada pela presença de interferentes.

\section{REFERÊNCIAS:}

CORRADINI, $\mathrm{C}$ et al. Antimicrobial films containing lysozyme for active packaging obtained by sol-gel techinique. J. Food Eng., Itália, p.589-587, 2013.

CUNHA, et. al., Desenvolvimento e avaliação de embalagem ativa com incorporação de lactase. Ciênc. Tecnol. Aliment., Campinas, p 23-26, ago. 2007.

SANTANA, Maria Cecília Castelo Branco de et al. Incorporação de urucum como aditivo antioxidante em embalagens biodegradáveis a base de quitosana. Ciência Rural, Santa Maria, v. 43, n. 2, p.1-7, fev. 2013.

SILVA, M. L. C. Desenvolvimento de filme ativo incorporado com poligalacturonase para uso em embalagem de suco de laranja. $115 \mathrm{f}$. Tese de Doutorado (Programa de Pós-Graduação em Biotecnologia) - Universidade Estadual de Feira de Santana, Feira de Santana, 2016.

SOARES, Nilda de Fátima Ferreira et al. Novos desenvolvimentos e aplicações em embalagens de alimentos. Revista Ceres, Viçosa, v. 56, n. 4, p.1-9, Jul./Ago., 2009.

WURLITZER, Nedio Jair. Desenvolvimento e avaliação de propriedades físicas e antimicrobianas de filmes poli(cloreto de vinilideno) incorporados com triclosan. 1962. 91f. Tese de Pós-Graduação (Doctor Scientiae) - Universidade Federal de Viçosa, Minas Gerais, 1962. 